\title{
Donor-Acceptor Substituted Thienylpyrrole Azo Dyes: Synthesis, Solvatochromic and Electrochemical Properties
}

\author{
M. Manuela M. Raposo, ${ }^{1, a^{*}}$ Ana M. R. C. Sousa, ${ }^{1, b}$ A. Maurício C. Fonseca ${ }^{1, c}$ \\ and G. Kirsch ${ }^{2, d}$
}

${ }^{1}$ Centro de Química, Universidade do Minho, Campus de Gualtar 4710-057 Braga, Portugal

2

Laboratoire d'Ingénierie Moléculaire et Biochimie Pharmacologique, UFR

SciFA/Université de Metz 1, Boulevard Arago, Metz Technopôle, 57078 Metz, France

a

e-mail: mfox@quimica.uminho.pt, e-mail: anacsousa@portugalmail.pt,

ce-mail: amcf@quimica.uminho.pt, e-mail: kirsch@sciences.univ-metz.fr

Keywords: donor-acceptor thienylpyrroles, azo dyes, UV-visible spectroscopy, chromophores, solvatochromism, electrochemistry, non-linear optical (NLO) material.

\begin{abstract}
The synthesis of thienyl- substituted pyrrole azo dyes and their UV-visible, solvatochromic and electrochemical properties are described. In agreement with the solvatochromic data and also with the electrochemical study the new donor-acceptor systems synthesized could have applications in NLO.
\end{abstract}

\section{Introduction}

The design and synthesis of organic chromophores as nonlinear optical (NLO) materials have attracted much attention in recent years. They have great potential especially for use in optical communication, information processing, frequency doubling and integrated optics [1]. Use of conjugated thiophene and pyrrole derivatives as donors combined with substituted acceptor groups are promising candidates among such D-A systems due to their numerous applications [2]. A renewed interest in aryl(heteroaryl)-azo dyes has been sparked by efforts to find organic secondorder non-linear optical (NLO) materials suitable for applications such as harmonic generation and optical switching. Azo dyes have particular interest because they can be readily prepared with a wide range of donor and acceptor groups and also because the planarity of the azo bridge versus the nonplanarity of stilbenes or other systems should contribute to the larger $\pi$ electron transmission effects and lead to higher optical activity [3-4]. As part of our continuing interest in non-linear optical material [5-11], we report in this paper the synthesis the solvatochromic and the electrochemical studies of new 1-alkyl(aryl)-2-(2'-thienyl)-5-phenylazopyrrole derivatives 1-2 which have the para $\mathrm{NO}_{2}$ and the ortho-para $\mathrm{NO}_{2}$ groups as the electron-withdrawing groups on the phenylazo moiety and the conjugated 1-alkyl(aryl)-2-(2'-thienyl)pyrrole, as strong $\pi$-electron donor moieties.

\section{Results and discussion}

Synthesis. Recently we have reported the synthesis of thienylpyrroles 3 through a combination of the Friedel-Crafts and the Lawesson reactions [11]. Compounds 3 have proved to be versatile substrates in azo coupling reactions, allowing the preparation of several new donor-acceptor substituted thienylpyrroles. The coupling reaction of aryldiazonium salts $4 a-b$, with thienylpyrroles $3 a-h$, in acetonitrile/acetic acid for $2 \mathrm{~h}$ at $0{ }^{\circ} \mathrm{C}$, give rise to the formation of 5-phenylazopyrrole derivatives $1 a-h$ and $2 d$. Diazo coupling was made selectively at the 5-position of pyrrole ring to give compounds $1-2$ in moderate to excelent yields (31-90\%), (Scheme 1, Table 1). These results are in accordance with the greater nucleophilicity of the pyrrole ring versus the thiophene ring as it 
has been shown earlier in the case of formylation of thienylpyrroles [12]. The structures of the thienylpyrrole azo dyes 1-2 were unambiguously confirmed by their analytical and spectral data.

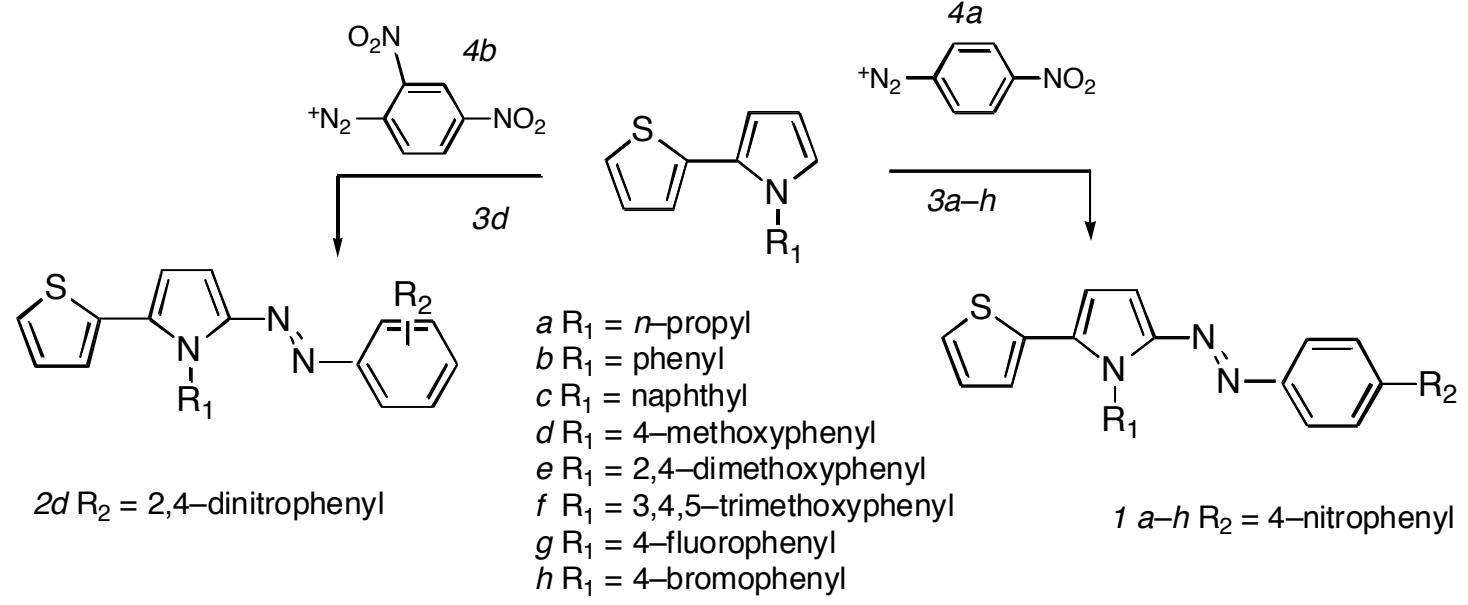

Scheme 1

Table 1- Yields and UV-visible data of pyrroles $3 a-h$ and pyrrole azo dyes $1 a-h$ and $2 d$.

\begin{tabular}{|c|c|c|c|c|c|c|c|c|}
\hline Entry & pyrrole & $\begin{array}{c}\lambda \max ^{*}[\mathrm{~nm}] \\
(\varepsilon)\end{array}$ & Azopyrrole & $\mathrm{R}_{1}$ & $\mathrm{R}_{2}$ & $\begin{array}{l}\text { Yield } \\
{[\%]}\end{array}$ & $\begin{array}{c}\lambda_{\max }{ }^{*}[\mathrm{~nm}] \\
(\varepsilon)\end{array}$ & $\begin{array}{l}\mathrm{h} v_{\text {ICT }} \\
{[\mathrm{eV}]}\end{array}$ \\
\hline 1 & $3 a$ & $291.0(1,800)$ & $1 a$ & $n$-propyl & $4-\mathrm{NO}_{2}$ & 63 & $488.0(25,100)$ & 2.54 \\
\hline 2 & $3 b$ & $294.5(9,208)$ & $1 b$ & phenyl & $4-\mathrm{NO}_{2}$ & 70 & $497.0(33,480)$ & 2.49 \\
\hline 3 & $3 c$ & $288.5(15,638)$ & $1 c$ & naphthyl & $4-\mathrm{NO}_{2}$ & 34 & $498.0(33,840)$ & 2.49 \\
\hline 4 & $3 d$ & $290.0(11,410)$ & $1 d$ & 4-methoxyphenyl & $4-\mathrm{NO}_{2}$ & 81 & $500.0(37,580)$ & 2.48 \\
\hline 5 & $3 e$ & $286.5(10,093)$ & le & $\begin{array}{c}2,4- \\
\text { dimethoxyphenyl }\end{array}$ & $4-\mathrm{NO}_{2}$ & 84 & $507.0(33,640)$ & 2.45 \\
\hline 6 & $3 f$ & $281.5(8,477)$ & $1 f$ & $\begin{array}{l}3,4,5- \\
\text { trimethoxyphenyl }\end{array}$ & $4-\mathrm{NO}_{2}$ & 88 & $499.0(33,520)$ & 2.48 \\
\hline 7 & $3 g$ & $293.0(8,505)$ & $\lg$ & 4-fluorophenyl & $4-\mathrm{NO}_{2}$ & 90 & $496.0(33,580)$ & 2.50 \\
\hline 8 & $3 h$ & $289.5(7,939)$ & $1 h$ & 4-bromophenyl & $4-\mathrm{NO}_{2}$ & 31 & $492.0(22,080)$ & 2.52 \\
\hline 9 & ---- & & $2 d$ & 4-methoxyphenyl & $2,4-\mathrm{diNO}_{2}$ & 47 & $531.0(38,420)$ & 2.34 \\
\hline
\end{tabular}

*All the UV/vis spectra were run in ethanol.

$\boldsymbol{U V}$-visible study. Electronic absorption spectra of all push-pull compounds $1 a-h$ and $2 d$ show an intense lowest energy charge-transfer absorption band in the UV-visible region. The position of this band is strongly influenced by the structure of the compounds, for example by the type of substitution pattern in the donor and the acceptor moieties. Dramatic differences in energy occur upon arylazo substitution of thienylpyrroles 3 . For example, pyrrole $3 d\left(\lambda_{\max }=290.0 \mathrm{~nm}\right)$ is shifted $241.0 \mathrm{~nm}$ upon arylazo substitution (thienylpyrrole azo dye $2 d, \lambda_{\max }=531.0 \mathrm{~nm}$ ) (Table 1). The influence of the strength of the acceptor group is demonstrated by comparison of the absorption maxima of compounds $1 d$ and $2 d$ as the longest wavelength transition is shifted from $500.0 \mathrm{~nm}$ in azopyrrole $1 d$ (Table 1, entry 4 ) to $531.0 \mathrm{~nm}$ for azopyrrole $2 d$ (Table 1, entry 9) and Figure 1 . This effect have been attributed to the stabilization of LUMO by the electron-withdrawing groups [13]. The influence of the substituent on the nitrogen atom of the pyrrole ring is demonstrated by comparison of the absorption maxima of compounds $l a$ and $l e$ as the longest wavelength transition 
is shifted from $488.0 \mathrm{~nm}$ in azopyrrole $1 a$ (Table 1, entry 1) to $507.0 \mathrm{~nm}$ for azopyrrole $1 e$ (Table 1 , entry 5). In general, the stronger the donor and/or acceptor group, the smaller the energy difference between ground and excited states, and the longer the wavelength of absorption [14]. According to Zyss [1] the increase of the $\beta$ values characteristic of the NLO effects is accompanied by an increase of the $\lambda_{\max }$ in the UV-visible spectra, i.e. a decrease in the intramolecular charge transfer (ICT) values.

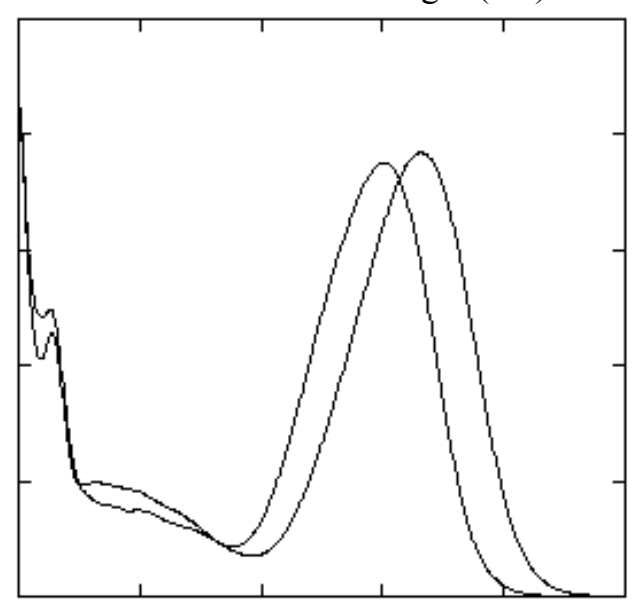

Figure 1- UV-vis. spectra of compounds $1 d$ and $2 d$ recorded in ethanol, demonstrating the electron-withdrawing effect of the acceptor group on the absorption maxima.

Solvatochromic study. To evaluate the intermolecular forces between the solvents and the solute molecules and in order to determine the best indicator dye, we made a preliminary study of the absorption spectra of compounds in selected solvents of different solvatation character (diethyl ether, ethanol and DMSO). We found that compound $1 d$ shows the longest shift in wavenumber maxima $\left(\Delta v_{\max }=801 \mathrm{~cm}^{-1}\right)$, probably due to the higher planarity of this conjugated system compared with $1 e$ and $2 d$. Therefore, $1 d$ was submitted to a full solvatochromic study involving 14 solvents (Table 2).

Table 2- Solvatochromic data $\left[\lambda_{\max }(\mathrm{nm})\right.$ and $v_{\max }\left(\mathrm{cm}^{-1}\right)$ of the charge-transfer band $]$ for azo dye $1 d$ in 14 solvents in comparison with $\pi^{*}$ values by Kamlet and Taft [15]

\begin{tabular}{cccc}
\hline Solvents & $\pi^{*}$ & \multicolumn{2}{c}{ Compound $1 d$} \\
& & $\lambda_{\max }[\mathrm{nm}]$ & $v_{\max }\left[\mathrm{cm}^{-1}\right]$ \\
\hline$n$-hexane & -0.008 & 478.0 & 20,920 \\
cyclohexane & 0.00 & 485.0 & 20,618 \\
diethyl ether & 0.27 & 490.0 & 20,408 \\
dioxane & 0.55 & 496.0 & 20,161 \\
ethyl acetate & 0.55 & 496.0 & 20,161 \\
tetrahydrofuran & 0.58 & 500.0 & 20,000 \\
acetone & 0.71 & 500.0 & 20,000 \\
acetonitrile & 0.75 & 508.0 & 19,685 \\
dimethylformamide & 0.88 & 510.0 & 19,607 \\
dimethylsulfoxide & 1.00 & 516.0 & 19,379 \\
ethanol & 0.54 & 500.0 & 20,000 \\
methanol & 0.60 & 500.0 & 20,000 \\
chloroform & $0.58 / 0.76[15]$ & 531.0 & 18,832 \\
dichloromethane & 0.82 & 528.0 & 18,939 \\
\hline
\end{tabular}

The highest energy transitions are found with nonpolar solvents such as hexane and cyclohexane. More polar solvents such as DMSO resulted in lower energy transitions. This behavior has been defined as a positive solvatochromic response $\left(\Delta v=+2088 \mathrm{~cm}^{-1}\right.$ for $\left.1 d\right)$ that is related to a greater 
stabilization of the excited state relative to the ground state with increasing polarity of the solvent. Because of the pronounced solvatochromism, the good correlation with $\pi^{*}$ values for the 14 solvents investigated $(\mathrm{r}=0.8450)$ and the long wavelength absorption in the visible range, $1 d$ seemed to be a very appropriate solvent polarity indicating dye. The change in dipole moment on electronic excitation was shown to be oriented parallel to the transition dipole and is moreover constant over the whole charge transfer band. Noteworthy is the behavior of compound $1 d$ in chlorinated solvents such as chloroform and dichloromethane which display the lowest energy transitions. Similar behavior has been observed for donor-acceptor substituted oligothiophenes where the trend was rationalized as a consequence of an intramolecular charge transfer [7, 14]. The great number of aliphatic and dipolar aprotic solvents was chosen to determine the correlation behavior of $v_{\max }(1 d)$ and $\pi^{*}$ because specific interactions were not expected. In fact a good correlation between absorption wavenumbers of $1 d$ and $\pi^{*}$ values $(\mathrm{r}=0.9750)$ of the corresponding solvents was obtained (Table 2).

Electrochemical study. To get as deeper insight into the ground state properties and more specifically the mutual donor-acceptor electronic influence, we studied the redox properties of pyrroles 3 and pyrrole azo dyes 1-2 by cyclic voltammetry and the results are presented in Table 3 . Upon diazo coupling, the thienylpyrrole azo dyes 1-2 display oxidations at more positive potentials as a consequence of the destabilizing effect of the electron-withdrawing group on the phenylazo moiety. For example thienylpyrrole azo dye $2 d$ displays an oxidation at ${ }^{1} \mathrm{E}_{\mathrm{pa}}=0.68 \mathrm{~V}$, an anodic shift of $0.20 \mathrm{~V}$ with respect to the unsubstituted thienylpyrrole $3 d$. An cathodic shift of oxidation peak potentials was observed with the increased of the donating capacity of the substituent group on the nitrogen atom of the pyrrole ring of thienylpyrrole precursors 3 and on the diazo dyes $1-2$. The pyrroles azo dyes 1-2 exhibit four redox processes, two oxidation and two reductions. In the anodic scan, the first of these processes is associated with the irreversible oxidation of the pyrrole moiety. These results are consistent with previous electrochemical studies of other pyrrole and thiophene derivatives [2], [16-17]. The second anodic feature is assigned to the irreversible oxidation of the azobenzene moiety [16]. Variation of the peak potential for oxidation of the pyrrole moiety reflect the magnitude of the electronic influence exerted upon the pyrrole ring system by the terminal electrodrawing substituent of the azoaryl group, e.g. azopyrrole $1 d$ display a first oxidation at ${ }^{1} \mathrm{E}_{\mathrm{pa}}=$ $0.62 \mathrm{~V}$ and azopyrrole $2 d$ display an oxidation at ${ }^{1} \mathrm{E}_{\mathrm{pa}}=0.68 \mathrm{~V}$. Cyclic voltammetry for all the compounds 1-2 shows a reversible reduction attributed to the azobenzene moieties [16]. The cathodic regime in the voltammetry of the pyrroles azo dyes, $1-2$, studied revealed two reversible couples. These correspond to the one electron reduction of the nitro $\left({ }^{1} \mathrm{E}_{1 / 2}\right)$ and azobenzene moieties $\left({ }^{2} \mathrm{E}_{1 / 2}\right)$, respectively. Communication between the electron donating and accepting termini can be evaluated by comparing the $\mathrm{E}_{1 / 2}$ values. A less negative half potential, suggests that the azobenzene unit is more facile to reduction (e.g. more electron rich). The extent of this interaction is dependent on the substituent group at the nitrogen atom on the pyrrole ring. For example, azopyrrole $1 a$ display a second reduction at ${ }^{2} \mathrm{E}_{1 / 2}=-1.70 \mathrm{~V}$ and azopyrrole $1 d$ display a reduction at ${ }^{2} \mathrm{E}_{1 / 2}=-1.83$ $\mathrm{V}$. These data are in line with the conclusion of the UV-visible study, which showed a lowering of the HOMO-LUMO gap with the increase of strength of the acceptor group in the arylazo moiety and with the substitution of an alkyl group for an aryl group on the nitrogen of the pyrrole ring.

\section{Conclusions}

In summary, we have achieved the first synthesis of a series of thienyl-substituted pyrrole azo dyes 1-2 in moderate to excellent yields. By comparing the several derivatives synthesized, it can be seen that the withdrawing group on the phenylazo moiety and the type of substituent on the nitrogen atom of the pyrrole ring have significant influence on the solvatochromic and the electrochemical properties. These derivatives exhibit dramatic changes in both their electronic and redox properties in comparison to the unsubstituted thienyl-pyrroles 3. To our knowledge, these are among the lowest band-gap materials based on thienylpyrrole derivatives. In agreement with the solvatochromic and the electrochemical studies of push-pull derivatives $1-2$ and also with previous 
findings [2-4] the new compounds prepared, can find application for manufacturing new materials with strong non-linear optical properties.

Table 3- Electrochemical data for thienyl-pyrroles 3 and pyrrole azo dyes $1-2^{\mathrm{a}}$.

\begin{tabular}{|c|c|c|c|c|c|c|}
\hline \multicolumn{2}{|c|}{ Thienylpyrroles 3} & \multicolumn{5}{|c|}{ Pyrroles azo dyes $1-2$} \\
\hline \multicolumn{3}{|c|}{ Oxidation } & \multicolumn{2}{|c|}{ Reduction } & \multicolumn{2}{|c|}{ Oxidation } \\
\hline Compound & $\mathrm{E}_{\mathrm{pa}}[\mathrm{V}]$ & Compound & $-{ }^{1} \mathrm{E}_{1 / 2}[\mathrm{~V}]$ & $-{ }^{2} \mathrm{E}_{1 / 2}[\mathrm{~V}]$ & ${ }^{1} \mathrm{E}_{\mathrm{pa}}[\mathrm{V}]$ & ${ }^{2} \mathrm{E}_{\mathrm{pa}}[\mathrm{V}]$ \\
\hline $3 a$ & 0.57 & $1 a$ & 1.23 & 1.70 & 0.78 & 0.96 \\
\hline $3 b$ & 0.53 & $1 b$ & 1.29 & 1.76 & 0.72 & 0.93 \\
\hline $3 c$ & 0.54 & $1 c$ & 1.31 & 1.80 & 0.72 & 0.92 \\
\hline $3 d$ & 0.48 & $1 d$ & 1.35 & 1.83 & 0.62 & 0.90 \\
\hline $3 e$ & 0.45 & $1 e$ & 1.36 & 1.77 & 0.61 & 0.90 \\
\hline $3 f$ & 0.46 & If & 1.35 & 1.81 & 0.63 & 0.91 \\
\hline $3 g$ & 0.55 & $\lg$ & 1.27 & 1.73 & 0.80 & 0.96 \\
\hline $3 h$ & 0.54 & $1 h$ & 1.25 & 1.72 & 0.79 & 0.97 \\
\hline ---- & ---- & $2 d$ & 1.40 & 1.76 & 0.68 & 0.93 \\
\hline
\end{tabular}

a Measurements made in $N, N$-dimethylformamide containing $0.1 \mathrm{~mol} \mathrm{dm}^{-3}\left[\mathrm{NBu}_{4}\right]\left[\mathrm{BF}_{4}\right]$ as base electrolyte at a carbon working electrode with a scan rate of $0.1 \mathrm{~V} \mathrm{~s}^{-1}$. Ferrocene was added as an internal standart at the end of each measurement, and all E values are quoted in volts versus the ferrocinium/ferrocene-couple.

\section{Acknowledgements}

Thanks are due to Foundation for Science and Technology (Portugal) for financial support through IBQF (UM) and through FEDER, POCTI (ref. POCTI/QUI/37816/2001) and also for a grant to A. M. R. C. Sousa.

\section{References}

[1] D.S. Chemla and J. Zyss: Non linear Optical Properties of Organic Molecules and Crystals, Vols. 1 and 2 (Academic Press, Orlando 1987).

[2] R. Zhao, M. Akazome, S. Matsumoto and K. Ogura: Tetrahedron Vol. 58 (51) (2002), p. 10225.

[3] A.D. Towns, Dyes Pigm.Vol. 42 (1) (1999), p. 3 and references cited therein.

[4] S.K. Yesodha, C.K.S. Pillai and N. Tsutsumi: Prog. Polym. Sci. Vol. 29 (1) (2004), p. 45.

[5] M.M.M. Raposo and G. Kirsch: Heterocycles Vol. 55 (8) (2001), p. 1487.

[6] M.M.M. Raposo and G. Kirsch: Tetrahedron Vol. 59 (26) (2003), p. 4891.

[7] M.M.M. Raposo, A.M.C. Fonseca and G. Kirsch: Tetrahedron Vol. 60 (18) (2004), p. 4071.

[8] M.M.M. Raposo, A.M.C. Fonseca and G. Kirsch: Mater. Sci. Forum, Vol. 455-456 (2004), p. 157.

[9] R.M.F. Batista, S.P.C. Costa and M.M.M. Raposo: Tetrahedron Lett. Vol. 45 (13) 2004, p. 2825.

[10] F. Costa, C.J.R. Silva, M.M.M. Raposo, A.M. Fonseca, I.C. Neves, A.P. Carvalho and J. Pires: Microporous Mesoporous Mater. Vol. 72 (1-3) (2004), p. 111.

[11] M.M.M. Raposo, A.M.B.A Sampaio and G. Kirsch: Synthesis Vol. 2 (2005), p. 199.

[12] A.H. Jackson: The Chemistry of Heterocyclic Compounds; Vol. 48 Part 1, p. 295, R. A. Jones editor, (Wiley, New York 1990) and references cited therein.

[13] J. Casado, T.M. Pappenfus, L.L. Miller, K.R. Mann, E. Orti, P.M. Viruela, R. Pou-Amerigo, V. Hernandez, and J.T.L. Navarrete: J. Am. Chem. Soc. Vol. 125 (9) (2003), p. 2524.

[14] F. Effenberger, F. Wuerthner, F. Steybe: J. Org. Chem. Vol. 60 (7) (1995), p. 2082.

[15] M.J. Kamlet, J.-L.M. Abboud, M.H. Abraham and R.W. Taft: J. Org. Chem. Vol. 48 (17) (1983), p. 2877 and references cited therein.

[16] Y. Chen, W.T.A. Harrison, C.T. Imrie and K.S. Ryder: J. Mater. Chem. Vol. 12 (3) (2002), p. 579.

[17] T. McCormac and D. Farrell: Electrochimica Acta Vol. 46 (20-21) (2001), p. 3287. 